\title{
Neurobehavioural effects of short duration exposures to acetone and methyl ethyl ketone
}

\author{
R B DICK, ${ }^{1}$ J V SETZER ${ }^{1}$ B J TAYLOR, ' R SHUKLA ${ }^{2}$ \\ From the Department of Health and Human Services,' Public Health Service, Centers for Disease Control, \\ National Institute for Occupational Safety and Health, Division of Biomedical and Behavioral Science, \\ Cincinnati, Ohio 45226, and Biostatistics-Epidemiology Laboratory, ${ }^{2}$ Department of Environmental Health, \\ University of Cincinnati Medical Center, Cincinnati, Ohio 45267-0056, USA
}

ABSTRACT A total of 137 volunteers were recruited and tested for neurobehavioural performance before, during, and after a short duration $(4 \mathrm{~h})$ exposure to acetone at $250 \mathrm{ppm}$, methyl ethyl ketone (MEK) at $200 \mathrm{ppm}$, acetone at $125 \mathrm{ppm}$ with MEK at $100 \mathrm{ppm}$, or a placebo. Ethanol $(95 \%-0.84 \mathrm{ml} /$ $\mathrm{kg}$ ) was used as a positive control. Performance testing was computer controlled and took place in an environmental chamber with four test stations. The total test regimen before, during, and after exposure covered 10 hours and 32 measures were collected. The measurements were extracted from two biochemical (venous blood and alveolar breath) tests, four psychomotor (choice reaction time, visual vigilance, dual task (auditory tone discrimination and tracking), memory scanning) tests, one sensorimotor (postural sway) test, and one psychological (profile of mood states (POMS)) test. The exposure to $250 \mathrm{ppm}$ acetone produced small but statistically significant changes in performance from controls in two measures of the auditory tone discrimination task and on the anger hostility scale (men only) of the POMS test. Neither MEK nor the combined acetone/MEK exposures produced statistically significant interpretable results. The combination exposure provides some indication that there was no potentiation of the acetone effects with the coexposure to MEK or vice versa. More pronounced performance decrements occurred with ethanol at 0.07-0.08\% BAC. Significant $(<0.05)$ differences were evident on both the auditory tone and tracking tests in the dual task and there was partial significance on the visual vigilance test $(0.05-0.06)$ and some postural sway measures $(<0.09)$. These findings agree with an earlier Japanese study in showing some mild decrements on behavioural performance tests with exposures to acetone at $250 \mathrm{ppm}$.

Workers are often exposed to combinations of industrial chemicals during manufacturing processes, degreasing operations, painting, and drycleaning. The purpose of this research was to study a combined exposure to two ketones, acetone and methyl ethyl ketone (MEK). Inhalation and skin contact are the primary routes of exposure, with the former being the most common due to their volatility at room temperature. Principal toxic effects on exposure to ketones are, progressively, eye, nose, and throat irritation, headache, nausea, vertigo, incoordination, depression of central nervous system, narcosis and, with extremely high exposures, cardiorespiratory failure. ${ }^{2}$

Neurobehavioural studies involving only single short duration exposures to acetone and MEK have been reported. Matsushita et al noted simple visual

Accepted 18 January 1988 reaction time increases in six subjects exposed for six hours a day for six successive days to 250 and $500 \mathrm{ppm}$ exposure concentrations. ${ }^{3}$ Nakaaki exposed two men and two women to $170-690 \mathrm{ppm}$ of acetone and reported some lengthening of response time on a time estimation test at concentrations above $450 \mathrm{ppm}{ }^{4}$ Exposures to MEK (90-270 ppm) caused some disruption on the time estimation test but only for the women. Dick et al exposed 20 subjects to $200 \mathrm{ppm}$ MEK for four hours and found no statistically significant effects on any of the performance tests during or after exposure. ${ }^{5}$

In the present study during a simulated eight hour workday subjects were given single exposures to acetone $(250 \mathrm{ppm})$ and MEK (200 ppm) at the NIOSH recommended exposure limits. ${ }^{6}$ Combined exposures (acetone $125 \mathrm{ppm} / \mathrm{MEK} 200 \mathrm{ppm}$ ) followed the United States OSHA additivity formula. ${ }^{7}$ Before, during, and after exposures, neurobehavioural and 
Table 1 Number of subjects by treatment conditions, sex, chemical, and subjects ratings of their condition. (Numbers in parentheses refer to number of subjects who reported they were exposed to a chemical or who reported they had had a drink containing ethanol)

\begin{tabular}{|c|c|c|c|c|c|c|c|c|c|}
\hline \multirow[b]{2}{*}{ Condition } & \multicolumn{3}{|c|}{ Men } & \multicolumn{3}{|c|}{ Women } & \multicolumn{3}{|l|}{ Total } \\
\hline & No & & $\% *$ & $N o$ & & $\%$ & No & & $\%$ \\
\hline $\begin{array}{l}\text { Acetone } \\
\text { Acetone/MEK } \\
\text { MEK } \\
\text { Chemical/placebo } \\
\text { Ethanol } \\
\text { Ethanol/placebo } \\
\text { Total }\end{array}$ & $\begin{array}{r}11 \\
8 \\
12 \\
11 \\
9 \\
11 \\
62\end{array}$ & $\begin{array}{r}(11) \\
(8) \\
(10) \\
(11) \\
(9) \\
(4) \\
(53)\end{array}$ & $\begin{array}{r}100 \\
100 \\
83 \\
100 \\
100 \\
36 \\
85\end{array}$ & $\begin{array}{l}11 \\
11 \\
13 \\
10 \\
11 \\
11 \\
66\end{array}$ & $\begin{array}{r}(9) \\
(10) \\
(7) \\
(6) \\
(10) \\
(4) \\
(45)\end{array}$ & $\begin{array}{l}82 \\
91 \\
54 \\
60 \\
91 \\
36 \\
68\end{array}$ & $\begin{array}{c}22 \\
19 \\
25 \\
21 \\
20 \\
22 \\
129 \dagger\end{array}$ & $\begin{array}{l}(20) \\
(18) \\
(17) \\
(17) \\
(19) \\
(8) \\
(99)\end{array}$ & $\begin{array}{l}91 \\
95 \\
68 \\
81 \\
95 \\
95 \\
77\end{array}$ \\
\hline
\end{tabular}

* Per cent of subjects reporting they were exposed or had ingested a drink containing ethanol.

†Six subjects eliminated from psychomotor data analysis for suspected use of marijuana (9-carboxy THC confirmed by GC/MS > 50 ng $\mathrm{ml})$. One subject for excessive alcohol (BAC > 0.03).

biochemical measurements were taken to determine whether performance decrements or enhancements would result from exposures to solvents.

\section{Materials and methods}

A total of 137 participants were tested over a one year period. They were recruited from local universities, ranged in age from 18 to 32 , and were required to pass a physical examination. Individuals with any preexisting medical condition such as pregnancy or hypertension were excluded. Urine analysis and breath analysis were used to exclude subjects (8 marijuana, 1 alcohol) for recent or chronic drug/ ethanol use. Equipment malfunctions reduced the number of subjects with usable data further, thus causing some imbalance in the number of subjects in each condition (see table 1).

\section{EXPERIMENTAL DESIGN}

The experiment was a mixed model (split plot factorial) design, with subjects treated as a random factor. The treatment conditions were: (1) acetone at $250 \mathrm{ppm}$, (2) MEK at $200 \mathrm{ppm}$, (3) acetone at $125 \mathrm{ppm}$ with MEK at $100 \mathrm{ppm}$, (4) chemical placebo, (5) $95 \%$ ethanol at $0.84 \mathrm{ml} / \mathrm{kg}$, and (6) ethanol placebo. Subjects were assigned to one of these treatment conditions after a forced randomisation scheme: equal numbers of men and women aged at least 21 for the ethanol conditions. Ethanol was used as a positive control and two placebo groups were used, one as a control for the chemical conditions and the other as an ethanol control. The chemical placebo consisted of five minute, $25 \mathrm{ppm}$ exposures to an acetone/MEK mixture presented twice during the four hour exposure period. The ethanol placebo was the ethanol drink mixture without ethanol. Self reported results from the end of the exposure test day questionnaire indicate that the chemical placebo was successful (table 1).
Experimental sessions were conducted double blin (subjects and experimenters) and in accordance with the guidelines of the National Institute for Occupational Safety and Health Human Subjects Review Board and the ethical principles of the American Psychological Association. Each voluntee was paid $\$ 135$ for participating. Testing took place 8 one of four test stations inside an environmenta chamber (Forma-Scientific) with interior dimension of $2.5 \mathrm{~m}$ wide $\times 5.3 \mathrm{~m}$ long $\times 2.2 \mathrm{~m}$ high. Each test station was configured with a Hewlett-Packard 13 118 video display terminal (VDT), a laboratory mode reaction time panel, one cylindrical microswith (Switchcraft E-19), two box mounted toggle switês (Switchcraft 41306), earphones (Realistic Pro-IIA and a pressure type joystick (Measurement System 735DC).

The three day testing regimen began with a two hour practice session on the day before the exposures. The exposure day was divided into four test periods lasting two hours each. The four hour exposure (middle two periods) was continuous except for a brief period fof body burden sampling. Figure 1 identifies the test

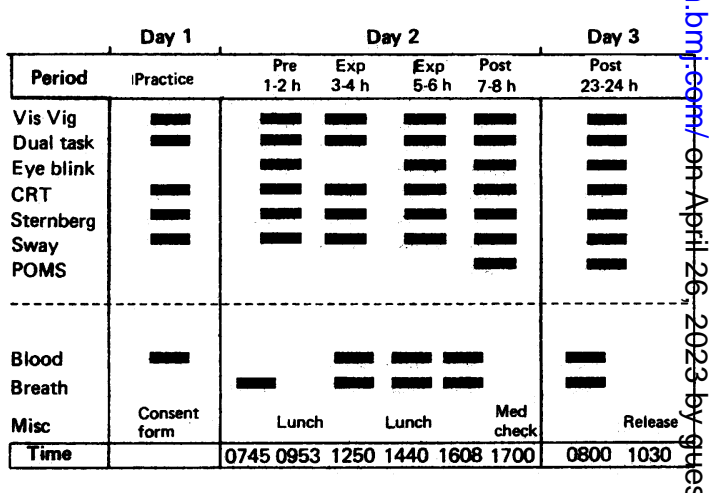

Fig 1 Experiment test schedule (order of performance test presentation reads top to bottom). 
periods, times of the blood and breath samples, lunch periods, performance test times, and various other procedural events. During the four hour exposure period, blood samples were divided, with half the subjects providing a two hour sample and the other half a four hour sample.

During each two hour test period, several measurements were taken, from which 32 were used for purposes of analysis. These measurements were derived from four psychomotor tests (choice reaction time (CRT), visual vigilance (VV), dual task, short term memory scanning (STM), one neurophysiological test (eye blink reflex), and one sensorimotor test (postural sway). One psychological test, profile of mood states (POMS), was administered to subjects at the end of the post: 7-8 $\mathrm{h}$ period and on the following day before the post: $23-24 \mathrm{~h}$ period.

\section{PERFORMANCE TESTS}

The neurobehavioural performance tests were controlled by an IBM series I computer and the postural sway test was run by a Northstar Horizon. Tests were presented simultaneously to the subjects and the order of test presentation (see fig 1) was the same in each test period. Trial order within a test, however, differed for each subject, and the trial order changed in each successive administration of the same test. Subjects were required to reach $80 \%$ criterion levels on tests requiring correct responses or a score between 60 and 90 for three minutes of tracking during the two hour testing practice session the day before. Twenty practice trials were given on the reaction time test and 30 on the memory scanning test while the remaining tests (eye blink and postural sway) were demonstrated.

\section{Visual vigilance}

The visual vigilance test was a computerised version of the Mackworth clock test. ${ }^{8}$ Centred on a VDT screen was a figure resembling a wagon wheel without a rim. Thirty spokes, equally separated by $12^{\circ}$, radiated from a central hub about $10 \mathrm{~mm}$ in diameter. Computerised graphics created the appearance of a moving clock hand jumping from one spoke to the next. The clockhand moved at 60 jumps a minute and the critical signal was a jump of two spokes $\left(24^{\circ}\right)$ which occurred in a random pattern. The 36 minute test had four nine minute periods with seven double jumps a period. Response time (msec) to double jumps, if it occurred within two seconds, correct hits, and false alarms were recorded.

\section{Dual task}

The dual test consisted of single presentations of an auditory tone discrimination task, a compensatory tracking task, and then the simultaneous (dual) presentation of both tasks. Each test segment took 10 minutes, with a one minute rest between presentation of the single and dual tasks. The auditory tone test, administered through earphones, required the detection of a $760 \mathrm{~Hz}$ tone from a series of $750 \mathrm{~Hz}$ tones. Tone duration was $250 \mathrm{msec}$, with a $750 \mathrm{msec}$ intratone interval. Sound levels were set at $61 \mathrm{db}$, using earphone measurements. Subjects received 600 tones, 18 of which were critical signals. The critical tones occurred randomly, at a rate of two a minute, with a minimum separation of 10 seconds. Response time to correct hits ( $\mathrm{msec})$, correct hits, misses, and false alarms were recorded.

The compensatory tracking task consisted of two $4 \mathrm{~cm} \mathrm{(L)} \times 0.38 \mathrm{~mm}$ (W) arrows, one pointing upward and one downward on a VDT screen. The downward arrow remained fixed in the centre of the screen, whereas the upward arrow oscillated horizontally across the screen, driven by one of three sine wave forcing functions of $0.1 \mathrm{~Hz}$ (10 second sweep). $0.067 \mathrm{~Hz}$ (15 second sweep), or $0.05 \mathrm{~Hz}(20$ second sweep). The forcing functions were presented in a Latin square stimulus pattern for the task difficulty parameter. The visual angle subtended by the moving arrow was $22^{\circ}$ with a linear distance of $22 \mathrm{~cm}$. Subjects used a joystick to reposition the moving arrow underneath the stationary arrow. The control display calibration was linear, with $16 \mathrm{~g}$ of pressure producing a $1^{\circ}$ visual angle displacement $(1 \mathrm{~cm})$. Presentation of a $5 \times 5 \mathrm{~cm}$ square in the centre of the screen was used to indicate excessive tracking error whenever the moving arrow was $5 \mathrm{~cm}$ in either direction from the stationary arrow. The tracking error measurement computed was a one minute average (366 samples/min) modulus mean error for each one minute of tracking at each task difficulty level. The first and last 30 seconds were excluded from tracking error scores.

In the dual task presentation the auditory tone discrimination test was paired with the tracking task. Tracking error, response time to correct hits, hits, and false alarms were recorded.

\section{Choice reaction time test}

The choice reaction time test was essentially the same as has been described previously. ${ }^{5}$ Displayed on a $16 \times 25 \mathrm{~cm}$ response panel are eight momentary push button switches with red translucent covers arranged in a semicircle above a single green button. Subjects were instructed to place the index finger of the preferred hand on the green button and only remove it when depressing a lighted red button. The test was self paced, with a minimum trial separation interval of $1500 \mathrm{msec} ; 96$ trials were presented each session. The first eight trials (warmup) and the last eight were discarded. On each trial, two reaction times were derived: release time, the interval between the onset of 
the red light and the subject's release of the green button, and movement time, the interval between the release of the green button and the depression of the appropriate red button.

\section{Memory scanning}

The memory scanning test was a computerised version of the Sternberg short term memory scanning test, ${ }^{9}$ which tests recognition memory. A varied set procedure was used to construct two 90 trial digit lists from random number tables and arranged into single trial list lengths of either two, four, or six monosyllable digits (1-9); they were rescrambled for successive presentations. All digit presentation positions were probed an equal number of times in set sizes 2 and 4 and in the first, second, fourth, and sixth of set size 6 . The probe digit was a test digit presented at the end of each list to test for retention of the previously memorised digits.

The digits were presented one at a time and appeared on a VDT screen for $900 \mathrm{msec}$ at $900 \mathrm{msec}$ intervals. At the end of each list presentation, there was a $900 \mathrm{msec}$ delay before the probe digit which appeared for $1500 \mathrm{msec}$. Subjects responded (yes or no) via the preferred hand toggle switch to indicate whether the probe digit matched any number in the previously presented list. The computer calculated six mean reaction times for each set size (list length) and probe type (positive or negative) that were used for generating slope and intercept scores for each subject.

\section{Postural sway (steadiness) test}

A computerised biomechanics platform system manufactured by Advanced Mechanical Technology, Inc (AMTI) was used for testing. User modifications to AMTI developed software provided analogue to digital readouts from six recording channels and included horizontal (torque) force components in the test calculations. Subjects were instructed to stand in stockinged feet on the platform in a set of footprints that had a $30^{\circ}$ separation angle, with hands at their side. Two 30 second tests (10/second sample rate), one with eyes closed and one with eyes open and counterbalanced on successive administrations, were recorded. Summary measures reported are: $\mathbf{R m}$-mean radius of sway in $\mathrm{cm}, \mathrm{Ys}$-standard deviations of centre pressure about the mean position in $\mathrm{cm}$, length-length of the sway path in $\mathrm{cm}$, Ao-area included within the sway path $\left(\mathrm{cm}^{2}\right)$, and velocity-mean velocity along sway path $(\mathrm{cm} / \mathrm{sec})$.

\section{Profile of mood states (POMS) ${ }^{10}$}

This test is a factor analysis derived inventory that measures six mood or affective states: tension-anxiety, depression-dejection, anger-hostility, vigour-activity, fatigue-inertia, and confusion-bewilderment. The test consisted of 65 five choice adjective rating scales an $\overline{\bar{B}}$ required about five minutes to complete. Subjects were instructed to: "include their feelings during the pas week including today" (one week POMS) in filling out. the test and it was scored using the "college norm" profile sheet.

The eye blink reflex test data will be reporte separately.

CHAMBER EXPOSURES/BODY BURDEN PROFILES Acetone and MEK were drawn from a reservoif through a dual high pressure metering pump (Eldex Model AA) into a 21 three vertical neck mixing flask where it was mixed with prepurified air to the desire concentration. Pressure in the mixing flask forced the vapour/air mixture into the chamber to produce the target concentration. Chamber airflows provided two fresh air changes an hour with a constant temperatures of $22 \pm 1^{\circ} \mathrm{C}$ and humidity of $50 \pm 5 \%$. Chamber atmospheres were sampled from ports calibrated to agree with the subjects' breathing zones at each of the four test stations. Both continuous (Miran 1A infraredanalysers) and periodic gas chromatography (Perkins? Elmer 3920) were used to monitor exposures. Table $\Phi$ summarises the chamber concentrations by sampling times using the more comprehensive data from the infrared analysers. Allowing for buildup in hour 1, a th exposure session concentrations were within $11 \%$ target concentrations for the four hour exposare period.

Breath (alveolar) and blood samples were colecs ted immediately on exit from the chamber. Breat samples were obtained in 51 mylar sampling bage using a 30 second breath holding method" and were analysed within 15 minutes using the gas

Table 2 Average chamber exposure concentrations by sample time

\begin{tabular}{|c|c|c|c|c|c|}
\hline \multirow[b]{2}{*}{ Measure (PPM) } & \multicolumn{5}{|c|}{ Exposure measurements } \\
\hline & Hour 1 & Hour 2 & Hour 3 & Hour 4 & $4 h$ mea \\
\hline $\begin{array}{l}\text { Acetone } 250 \text { ppm } \\
\text { Mean } \\
\text { SD } \\
\text { n }\end{array}$ & $\begin{array}{c}204.6 \\
17 \cdot 6 \\
9\end{array}$ & $\begin{array}{c}250 \\
4 \cdot 3 \\
9\end{array}$ & $\begin{array}{c}245 \cdot 2 \\
3 \cdot 9 \\
9\end{array}$ & $\begin{array}{c}249 \cdot 4 \\
4 \cdot 3 \\
9\end{array}$ & $\begin{array}{c}237 \cdot 4 \\
4 \cdot 4 \\
9\end{array}$ \\
\hline $\begin{array}{l}\text { Methyl ethyl keto } \\
\text { Mean } \\
\text { SD } \\
\text { n }\end{array}$ & $\begin{array}{c}\text { ne } 200 \mathrm{pl} \\
155 \cdot 1 \\
26 \cdot 3 \\
8\end{array}$ & $\begin{array}{c}\text { m: } \\
197.0 \\
4 \cdot 7 \\
8\end{array}$ & $\begin{array}{c}194 \cdot 5 \\
9 \cdot 4 \\
8\end{array}$ & $\begin{array}{c}198 \cdot 5 \\
6 \cdot 7 \\
8\end{array}$ & $\begin{array}{c}186 \cdot 3 \\
4 \cdot 8 \\
8\end{array}$ \\
\hline $\begin{array}{l}\text { Acetone } 125 \text { ppm } \\
\text { Mean } \\
\text { SD } \\
n\end{array}$ & $\begin{array}{l}\text { (combin } \\
100 \cdot 5 \\
17 \cdot 2 \\
8\end{array}$ & $\begin{array}{c}\text { tion): } \\
120.7 \\
11.7 \\
8\end{array}$ & $\begin{array}{c}118 \cdot 4 \\
7 \cdot 9 \\
8\end{array}$ & $\begin{array}{c}121 \cdot 2 \\
3 \cdot 2 \\
8\end{array}$ & $\begin{array}{c}115 \cdot 2 \\
5 \cdot 6 \\
8\end{array}$ \\
\hline $\begin{array}{l}\text { Methyl ethyl keto } \\
\text { Mean } \\
\text { SD } \\
\text { n }\end{array}$ & $\begin{array}{c}\text { ne } 100 \mathrm{pl} \\
72 \cdot 6 \\
13 \cdot 2 \\
8\end{array}$ & $\begin{array}{c}\text { m (combi } \\
94 \cdot 6 \\
9 \cdot 7 \\
8\end{array}$ & $\begin{array}{c}\text { nation): } \\
91.6 \\
9.9 \\
8\end{array}$ & $\begin{array}{c}93 \cdot 3 \\
13 \cdot 0 \\
8\end{array}$ & $\begin{array}{c}88 \cdot 1 \\
9 \cdot 3 \\
8\end{array}$ \\
\hline
\end{tabular}

$\mathrm{n}=$ Number of exposure sessions. 
chromatograph. Blood samples were collected from the antecubital vein in $5 \mathrm{ml}$ heparinised glass tubes and analysed within 24 hours by gas liquid chromatography, using a head space technique. Confirmation of the blood and breath concentrations are summarised in table 3. A more extensive report is available. ${ }^{12}$

\section{Ethanol administration}

The ethanol $(0.84 \mathrm{ml} / \mathrm{kg})$ cocktail contained a calculated concentration of $95 \%$ ethanol, $100 \mathrm{ml}$ quinine water, $75 \mathrm{cc}$ of orange juice, two drops of tabasco sauce, and crushed ice. Additional quinine and orange juice replaced ethanol in the placebo cocktail. Subjects were given 20 minutes to consume the drink.

\section{Results}

The four chemical exposure groups were analysed separately from the two ethanol groups because of differences in administering the treatment (ingestion versus inhalation) and by multivariate techniques (MANOVA) using difference scores. The pre: $1-2 \mathrm{~h}$ scores served as the baseline values and were subtracted from the scores in the other periods to produce three difference scores. The mood test, which was administered only twice, produced only one difference score. Data from the test period on the day after exposure were used primarily to test for learning or practice effects, which were evident in only the choice reaction time test and the memory scanning test. Per cent data were calculated as follows: $\%$ correct hits = correct hits divided by expected hits $\times 100$, and false alarms $\%=$ false alarms divided by false alarms + correct hits $\times 100$. Two measures in the visual vigilance test (\% correct hits and false alarm \%) required arc sine transformations to normalise the data distribution.

General linear model (GLM) analysis programs using version $5 \cdot 15$ of $\mathrm{SAS}^{13}$ were used to accommodate unequal cell frequencies when model size permitted. The MANOVA test statistic reported is the Wilks's Lambda. To control for an experimentwise error problem (type I), ${ }^{14}$ but still retain sufficient power to detect treatment effects, significant results were determined using the Hummel-Sligo procedure. ${ }^{15}$ This procedure specified that significance was necessary on both the multivariate and univariate analysis at a predetermined alpha (0.05). Least-squares means (LSM) comparisons were used to identify treatment group differences on an a priori basis, except for the postural sway analysis which used Duncan's multiple range and Student Newman-Keuls tests. The only comparisons considered were the placebo groups versus their respective treatment groups for the same test period.

Initial analysis of all the behavioural tests indicated that sex differences did not qualitatively or statistically differ. As a result, except for the POMS test which has shown sex differences on some of the factor scores, ${ }^{16}$ the sexes were combined for analysis. The results are summarised in table 4 . The dual task analyses

Table 3 Blood and breath concentrations*

\begin{tabular}{|c|c|c|c|c|c|}
\hline Condition & Pre & $2 h$ & $4 h$ & $90 \mathrm{~m}$ post & 20 h post \\
\hline \multicolumn{6}{|c|}{ Blood concentration $(\mu \mathrm{g} / \mathrm{ml}$ or $w / v \%) \ddagger$} \\
\hline $\begin{array}{l}\text { Control } \neq(n=21) \\
\text { AC-S }(n=22) \\
\text { MEK-S }(n=26) \\
\text { AC-C }(n=22) \\
\text { MEK-C }(n=22) \\
\text { Ethanol† }(n=21)\end{array}$ & $\begin{array}{l}1.5 \pm 0.8(\mathrm{ND}-3.7) \\
2.0 \pm 2.0(\mathrm{ND}-8.6) \\
\mathrm{ND} \\
1.9 \pm 1.0(\mathrm{ND}-4.4) \\
\mathrm{ND} \\
<0.002(0.0-0.002)\end{array}$ & $\begin{array}{l}1 \cdot 0 \pm 0.4(\mathrm{ND}-1 \cdot 5) \\
9 \cdot 0 \pm 2.0(6 \cdot 3-13.5) \\
3 \cdot 1 \pm 1 \cdot 1(1 \cdot 1-4 \cdot 8) \\
6 \cdot 2 \pm 1 \cdot 8(4 \cdot 3-10 \cdot 4) \\
1 \cdot 1 \pm 0.3(0.7-1 \cdot 7) \\
0.062 \pm 0.010 \\
(0.04-0.078)\end{array}$ & $\begin{array}{l}1 \cdot 7 \pm 1 \cdot 3(0 \cdot 5-4 \cdot 8) \\
15 \cdot 3 \pm 2 \cdot 9(11 \cdot 6-19 \cdot 6) \\
3 \cdot 5 \pm 1 \cdot 5(1 \cdot 3-6 \cdot 1) \\
10 \cdot 4 \pm 2 \cdot 4(6 \cdot 9-14 \cdot 8) \\
1.9 \pm 0 \cdot 9(1 \cdot 0-3 \cdot 8) \\
\text { No sample }\end{array}$ & $\begin{array}{l}1 \cdot 3 \pm 0.6(0.6-3 \cdot 6) \\
11.9 \pm 2 \cdot 6(9 \cdot 0-18 \cdot 7) \\
1 \cdot 0 \pm 0.6(0 \cdot 2-2 \cdot 6) \\
8 \cdot 0 \pm 2 \cdot 1(4 \cdot 2-12 \cdot 3) \\
0.5 \pm 0.3(0 \cdot 1-1 \cdot 3) \\
0.007 \pm 0 \cdot 007 \\
(0.0-0.026)\end{array}$ & $\begin{array}{l}1.3 \pm 0.6(0.7-2.9) \\
1.5 \pm 1.0(0.5-5.0) \\
\mathrm{ND} \\
1.6 \pm 1.3[\mathrm{ND}-6.2) \\
\mathrm{ND} \\
<0.001(0.0-0.004)\end{array}$ \\
\hline \multicolumn{6}{|c|}{ Breath concentration (ppm) } \\
\hline $\begin{array}{l}\text { Control } \neq(n=21) \\
\text { AC-S }(n=22) \\
\text { MEK-S }(n=26) \\
\text { AC-C }(n=22) \\
\text { MEK-C }(n=22) \\
\text { Ethanol† }(n=21)\end{array}$ & $\begin{array}{l}0.3 \pm 0.6(\mathrm{ND}-2.0) \\
0.4 \pm 0.6(\mathrm{ND}-1.5) \\
\mathrm{ND} \\
0.3 \pm 0.7(\mathrm{ND}-3.1) \\
\mathrm{ND} \\
<0.01\end{array}$ & $\begin{array}{l}0 \cdot 1 \pm 0 \cdot 2(\text { ND- } 0.8) \\
21 \cdot 5 \pm 4 \cdot 4(15 \cdot 6-34 \cdot 0) \\
11.4 \pm 3 \cdot 0(7.0-18 \cdot 5) \\
12.9 \pm 3 \cdot 3(7 \cdot 4-19 \cdot 2) \\
5 \cdot 1 \pm 2 \cdot 9(1.4-13 \cdot 1) \\
179 \cdot 1 \pm 28 \cdot 3 \\
(137.0-239 \cdot 8)\end{array}$ & $\begin{array}{l}0 \cdot 3 \pm 0.5(\text { ND-1.8) } \\
25 \cdot 8 \pm 4 \cdot 0(18 \cdot 6-34 \cdot 0) \\
11.9 \pm 3 \cdot 0(7 \cdot 4-19 \cdot 2) \\
15 \cdot 3 \pm 2 \cdot 7(10 \cdot 6-20 \cdot 6) \\
5 \cdot 3 \pm 1 \cdot 9(2 \cdot 7-11 \cdot 5) \\
85 \cdot 8 \pm 38 \cdot 1 \\
(15 \cdot 4-152 \cdot 5)\end{array}$ & 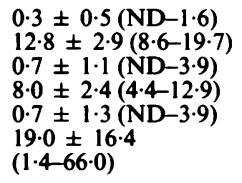 & $\begin{array}{l}0.4 \pm 0.7(\mathrm{ND}-2.8) \\
0.6 \pm 0.8(\mathrm{ND}-2.8) \\
\mathrm{ND} \\
0.6 \pm 0.8(\mathrm{ND}-4.9) \\
\mathrm{ND} \\
<0.01\end{array}$ \\
\hline
\end{tabular}

${ }^{*}$ Values are means \pm SD for the substance adminstered. Values in parentheses are ranges. Sample times are from beginning of exposure or ingestion of ethanol, except for the pre-exposure samples (see text). All subjects were sampled for ethanol, acetone, and MEK. Pre and post acetone values for the other groups corresponded to the control values reported for the chemical control group. MEK and ethanol values for the other groups were non-detectable (MEK) or $<0.01$ (ethanol).

tEthanol values are given in $w / v \%$ which corresponds to $\%$ blood alcohol concentration.

fControl values are for the chemical placebo group (acetone only, as MEK was not detected). The ethanol placebo group values were all less than 0.003 (blood) or 0.01 (breath) or subject was rejected.

AC-S (acetone $250 \mathrm{ppm}$ ).

MEK-S (methyl ethyl ketone 200 ppm).

AC-C (combination-acetone $125 \mathrm{ppm}$ ).

MEK-C (combination-methyl ethyl ketone $100 \mathrm{ppm})$

Ethanol (0.84 ml $/ \mathrm{kg} \mathrm{95 \%} \mathrm{ethanol).}$

$\mathrm{ND}=$ Not detectable, $100 \%$ of values below detectable limits. 
Table 4 Summary results of statistical analysis on the dual task, visual vigilance, choice reaction time, memory scanning, postural sway, and POMs tests

\begin{tabular}{|c|c|c|c|c|}
\hline \multirow{2}{*}{$\frac{\text { Test }}{\text { Dual task }}$} & \multicolumn{2}{|c|}{$\begin{array}{l}\text { Chemical conditions } \\
M A N O V A \text { ANOVA }\end{array}$} & \multicolumn{2}{|c|}{$\begin{array}{l}\text { Ethanol conditions } \\
\text { MANOVA ANOVA }\end{array}$} \\
\hline & + & $+*$ & + & $+*$ \\
\hline Visual vigilance & - & - & $+t$ & $+t$ \\
\hline Choice reaction time & - & - & + & $+\stackrel{+}{\S}$ \\
\hline Memory scanning & + & $+\|$ & - & - \\
\hline Postural sway & - & - & +9 & - \\
\hline POMS & + & $+* *$ & - & - \\
\hline
\end{tabular}

$+=$ Statistically significant at the 0.05 alpha level.

_ = Not statistically significant at the 0.05 alpha level.

* Statistically significant on several measures (see text and table 5).

tp $<0.0581$.

False alarm \% rate in exp: $5-6 \mathrm{~h}$ period.

\$Movement time in post: 7-8 $\mathrm{h}$ test period.

NNegative intercept in exp: $5-6 \mathrm{~h}$ and post: 7-8 $\mathrm{h}$ period (see text). If $<0.09$ (see text).

* For men only in acetone group on the anger hostility scale.

produced the most significant results, so this test is presented separately and in more detail (table 5).

DUAL TASK

Owing to the size of the data set and the number of variables concerned a top down approach was used $\overline{\bar{Q}}$ Initial analysis of combined scores for the four response variables in single and dual presentations showed statistically significant MANOVA/ANOVA results for the chemical treatment groups only in singles? presentation, whereas with the ethanol groups, alt response variables in both presentation formatso indicated significant differences.

Subsequent single presentation analyses showed no significant MANOVAs for chemical or ethanol condition effects on tracking performance but there weres significant chemical condition effects in the auditory. task [MANOVA-F $\quad(9,197)=2.52 \quad \mathrm{p}<0.009] \vec{\overrightarrow{ }}$ Examination of the univariate analyses in the auditory tone single presentation (chemical groups) showedo significant effects on response time (condition $=p<0.05$ ) and false alarm \% (condition = $p<0.005$ ) but not on per cent correct hits (condition $=\mathrm{p}<0.33$ ).

Chemical treatment group comparisons (LSM) with controls showed significant differences only with the acetone group for response time (table 5) in the exp: 3 $4 \mathrm{~h}$ period $(\mathrm{p}<0.002)$ and in the post: $7-8 \mathrm{~h}$ period

Table 5 Dual task performance measurements by presentation (single $v$ dual), period, and chemical condition

\begin{tabular}{|c|c|c|c|c|c|c|c|c|c|c|c|}
\hline \multirow[b]{2}{*}{$\begin{array}{l}\text { Resp } \\
\text { measure† }\end{array}$} & \multicolumn{8}{|c|}{ Time periodst } & & & \multirow{2}{*}{ 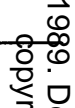 } \\
\hline & $\begin{array}{l}\text { Pre: } 1-2 h \\
S\end{array}$ & $D$ & $\begin{array}{l}\text { Exp: } 3- \\
S\end{array}$ & $D$ & $\begin{array}{l}\text { Exp: } 5-6 \\
S\end{array}$ & $D$ & $\begin{array}{l}\text { Post: } 7 \\
S\end{array}$ & $D$ & $\begin{array}{l}\text { Post } \\
S\end{array}$ & $\begin{array}{l}h \\
D\end{array}$ & \\
\hline $\begin{array}{l}\text { Acetone }(n=22): \\
\text { Resp time } \\
\% \text { Corr hits } \\
\text { False alarm }(\%) \\
\text { Trk error|| }\end{array}$ & $\begin{array}{r}617 \\
92 \\
28 \\
93\end{array}$ & $\begin{array}{r}648 \\
89 \\
27 \\
93\end{array}$ & $\begin{array}{l}694^{* *} \\
84 \\
30^{* * *} \\
104\end{array}$ & $\begin{array}{r}681 \\
84 \\
29 \\
98\end{array}$ & $\begin{array}{l}684 \\
80 \\
30^{* * * *} \\
98\end{array}$ & $\begin{array}{r}726 \\
81 \\
28 \\
93\end{array}$ & $\begin{array}{l}738^{* * *} \\
79 \\
35^{* * * *} \\
110\end{array}$ & $\begin{array}{r}745 \\
78 \\
34 \\
116\end{array}$ & $\begin{array}{r}686 \\
85 \\
33 \\
97\end{array}$ & $\begin{array}{r}693 \\
88 \\
33 \\
99\end{array}$ & 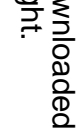 \\
\hline $\begin{array}{l}\text { Acetone/MEK (n = } \\
\text { Resp time§ } \\
\% \text { Corr hits } \\
\text { False alarm (\%) } \\
\text { Trk error|l }\end{array}$ & $\begin{array}{r}19): \\
681 \\
80 \\
27 \\
105\end{array}$ & $\begin{array}{r}704 \\
82 \\
21 \\
108\end{array}$ & $\begin{array}{c}690 \\
78 \\
21^{*} \\
109\end{array}$ & $\begin{array}{r}723 \\
81 \\
21 \\
112\end{array}$ & $\begin{array}{l}700 \\
79 \\
21^{* * *} \\
111^{*}\end{array}$ & $\begin{array}{r}744 \\
80 \\
25 \\
124\end{array}$ & $\begin{array}{c}756 \\
70 \\
21^{* *} \\
122\end{array}$ & $\begin{array}{r}792 \\
75 \\
22 \\
120\end{array}$ & $\begin{array}{r}709 \\
83 \\
24 \\
113\end{array}$ & $\begin{array}{r}706 \\
83 \\
23 \\
111\end{array}$ & $\begin{array}{l}\stackrel{\overrightarrow{7}}{0} \\
\frac{2}{3} \\
\frac{\sqrt{\rightleftarrows}}{\overrightarrow{0}}\end{array}$ \\
\hline $\begin{array}{l}\text { MEK }(n=25): \\
\text { Resp time } \$ \\
\% \text { Corr hits } \\
\text { False alarm (\%) } \\
\text { Trk error\| }\end{array}$ & $\begin{array}{r}671 \\
82 \\
23 \\
95\end{array}$ & $\begin{array}{r}660 \\
87 \\
24 \\
98\end{array}$ & $\begin{array}{l}658 \\
83 \\
17^{*} \\
97\end{array}$ & $\begin{array}{r}697 \\
82 \\
21 \\
101\end{array}$ & $\begin{array}{l}670 \\
80 \\
16^{* * * *} \\
102\end{array}$ & $\begin{array}{r}760 \\
78 \\
16 \\
101\end{array}$ & $\begin{array}{c}693 \\
74 \\
20^{* *} \\
103\end{array}$ & $\begin{array}{r}727 \\
80 \\
18 \\
97\end{array}$ & $\begin{array}{r}693 \\
84 \\
18 \\
90\end{array}$ & $\begin{array}{r}728 \\
83 \\
16 \\
95\end{array}$ & $\frac{\bar{O}}{3}$ \\
\hline $\begin{array}{l}\text { Chemical placebo ( } \\
\text { Resp time } \\
\text { \% Corr hits } \\
\text { False alarm (\%) } \\
\text { Trk error|l }\end{array}$ & $\begin{array}{l}n=21): \\
635 \\
90 \\
32 \\
101\end{array}$ & $\begin{array}{r}638 \\
88 \\
21 \\
104\end{array}$ & $\begin{array}{r}638 \\
88 \\
19 \\
106\end{array}$ & $\begin{array}{r}663 \\
89 \\
18 \\
112\end{array}$ & $\begin{array}{r}678 \\
82 \\
15 \\
112\end{array}$ & $\begin{array}{r}696 \\
80 \\
20 \\
107\end{array}$ & $\begin{array}{r}691 \\
79 \\
16 \\
115\end{array}$ & $\begin{array}{r}708 \\
84 \\
18 \\
111\end{array}$ & $\begin{array}{r}638 \\
91 \\
20 \\
103\end{array}$ & $\begin{array}{r}670 \\
90 \\
19 \\
100\end{array}$ & $\frac{\substack{0 \\
3}}{0}$ \\
\hline $\begin{array}{l}\text { Ethanol }(n=20): \\
\text { Resp time } \\
\% \text { Corr hits } \\
\text { False alarm }(\%) \\
\text { Trk error|| }\end{array}$ & $\begin{array}{r}660 \\
92 \\
26 \\
102\end{array}$ & $\begin{array}{r}696 \\
93 \\
15 \\
99\end{array}$ & $\begin{array}{l}731^{* * *} \\
82^{*} \\
12^{* * *} \\
118\end{array}$ & $\begin{array}{l}781^{* * *} \\
83^{* * *} \\
15 \\
122^{* * *}\end{array}$ & $\begin{array}{c}741^{* * * *} \\
72^{* * * *} \\
16^{* * *} \\
121\end{array}$ & $\begin{array}{c}778 * * * \\
79 * * * \\
17 \\
122 * * *\end{array}$ & $\begin{array}{r}739^{* *} \\
72^{* *} \\
13^{* *} \\
114\end{array}$ & $\begin{array}{l}766 \\
79^{* * * *} \\
11 \\
116\end{array}$ & $\begin{array}{r}697 \\
87 \\
18 \\
92\end{array}$ & $\begin{array}{r}729 \\
87 \\
18 \\
96\end{array}$ & $\frac{\text { D }}{\text { Oํ. }}$ \\
\hline $\begin{array}{l}\text { Ethanol placebo (n } \\
\text { Resp time§ } \\
\text { \% Corr hits } \\
\text { False alarm (\%) } \\
\text { Trk error|| }\end{array}$ & $\begin{array}{l}=22): \\
627 \\
88 \\
19 \\
113\end{array}$ & $\begin{array}{r}611 \\
85 \\
19 \\
106\end{array}$ & $\begin{array}{r}617 \\
86 \\
18 \\
111\end{array}$ & $\begin{array}{r}630 \\
88 \\
18 \\
108\end{array}$ & $\begin{array}{r}628 \\
87 \\
17 \\
114\end{array}$ & $\begin{array}{r}617 \\
87 \\
17 \\
109\end{array}$ & $\begin{array}{r}651 \\
78 \\
15 \\
119\end{array}$ & $\begin{array}{r}686 \\
90 \\
21 \\
119\end{array}$ & $\begin{array}{r}610 \\
91 \\
25 \\
102\end{array}$ & $\begin{array}{r}639 \\
92 \\
21 \\
104\end{array}$ & $\begin{array}{l}\text { O } \\
N \\
\omega \\
\sigma\end{array}$ \\
\hline $\begin{array}{l}{ }^{*} \mathrm{p}=0.05 ;{ }^{*} \mathrm{p}=0 \\
+ \text { Group means und } \\
+ \text { Refers to number } \\
\text { §Response time is in } \\
\text { \|ाTracking error is } \mathrm{T}\end{array}$ & $\begin{array}{l}0.01 ; * *{ }^{*} \mathrm{p}= \\
\text { ler single }(\mathrm{S}) \\
\text { of hours sin } \\
\mathrm{n} \text { msec. } \\
\text { nodulus mea }\end{array}$ & $\begin{array}{l}0.00 \\
\text { and } \\
\text { ce beg } \\
\text { an err }\end{array}$ & $\begin{array}{l}\text { prese } \\
\text { f test }\end{array}$ & $\begin{array}{l}\text { modes } \\
\text {. }\end{array}$ & & & & & & & 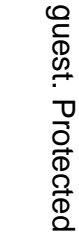 \\
\hline
\end{tabular}


(p < 0.006). Response time increases from baseline averaged $12 \%$ and $11 \%$, respectively, over controls for the two significant test periods. The exp: $5-6 \mathrm{~h}$ test period, which was not significant, showed a $4 \%$ increase over controls. All chemical treatment groups differed significantly from the control group on false alarm $\%$ in all three test periods (see table 5). Averaging scores across all three test periods, the acetone group's false alarm $\%$ increased by $4 \%$, whereas the control group decreased $16 \%$. For the acetone/MEK group, there was a $4 \%$ decrease, and for the MEK group the decrease was $5 \%$. The treatment effects were the most dramatic for the acetone group, and more clearly indicate a chemical effect. The other two chemical groups changed in the same direction as the control group, and their differences may be due more to the baseline performance of the control group. The control group's improvement from baseline testing was substantial in the exp: 3-4 h period, where it closely parallelled the performance of the acetone/ MEK and MEK groups. Similar performance levels continued for the remaining test periods (see figure 2).

Ethanol effects were also present in both the auditory tone single presentation (MANOVA, condition $F(3,38)=6.39, p<0.001)$ and in the dual presentation with tracking task difficulty included (MANOVA, condition F $(3,38)=3.77, \mathrm{p}<0.018)$. In the latter analysis tracking task difficulty produced no significant interactions with condition, so only the analysis which used overall mean tracking scores is reported in table 5 . In the single auditory tone analysis significant effects were found in the univariate analyses
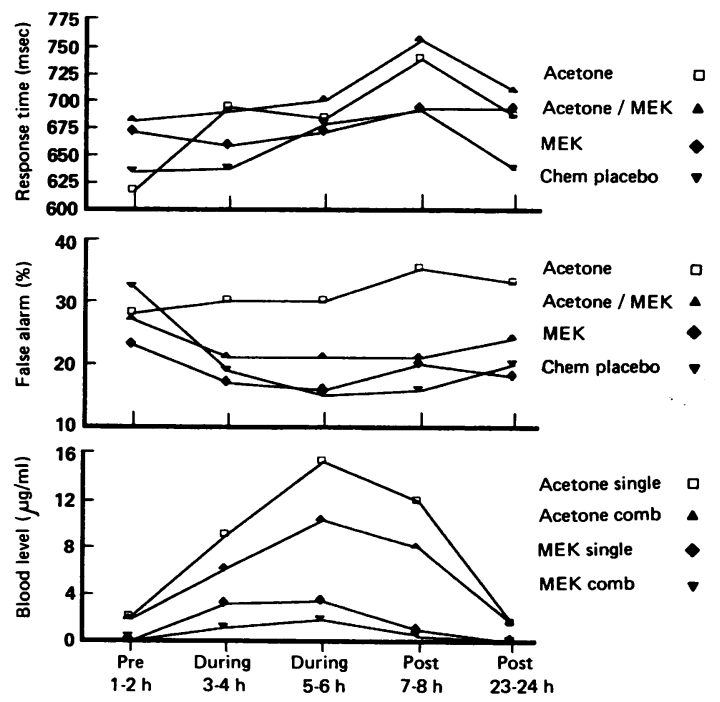

Fig 2 Response time, false alarm \% rate on the auditory tone discrimination task (single presentation), and venous. blood levels for each chemical condition. on all response variables in all three test periods. Ethanol produced significant MANOVAs in dual presentation for condition $(F(4,37)=4.79$, $p<0.003$ ) and (condition $\times$ time (period)-F $(8,152)=2.02, p<0.048)$. Significant effects from univariate analyses $(p<0.05$ to $p<0.001)$ occurred with response time (exposure periods), \% correct hits (all periods), and tracking (exposure periods). Compared with controls, the ethanol group's performance showed: average response time increases $(12 \%)$, average tracking score increases $(20 \%)$, and average decreases in \% correct hits (11\%) (fig 3).

In summary, chemical effects were noted in the auditory tone single presentation for all three chemical groups on false alarm \%, and for acetone only, on response time. Chemical effects were the most pronounced for the acetone group; less so for the MEK or acetone/MEK group. No chemical effects were evident on the auditory tone task in dual presentation. Ethanol effects were present on all response variables in the auditory tone single presentation but only on response time and \% correct hits in dual presentation. Tracking performance was not affected by the chemical conditions in either single or dual presentation, nor did ethanol affect tracking performance in single presentation. Ethanol did cause significant increases in tracking error in dual presentation.

\section{VISUAL VIGILANCE}

Initial analysis determined there was no shift in the vigilance decrement (condition $\times$ time interaction) due to a condition effect. With the time periods omitted as a factor, MANOVAs were run for chemical and ethanol effects. No chemical condition effects were evident: condition $(F(9,236)=1 \cdot 12, p<0 \cdot 351)$, condition $\times$ period (test period) $(F(18,479)=0.54$, $p<0.939$ ). Some effects existed in the ethanol condition, however: condition $\times$ period $(F(6,154)=2 \cdot 08$, $\mathrm{p}<0.0581)$. The only significant result from univariate analysis was a period $\times$ condition $(p<0.02)$ effect on false alarm \% in the exp: $5-6 \mathrm{~h}$ period (LSM $p<0.002$ ). The change was a $13 \%$ increase over baseline compared with the control group's $4 \%$ increase. These results are summarised in fig 4.

\section{CHOICE REACTION TIME}

No significant differences between the chemical treatment groups were indicated by the multivariate analysis for condition $(F(6,160)=1 \cdot 18, p<0.322)$ or condition $\times$ period $(F(12,322)=1 \cdot 29, p<$ $0 \cdot 223$ ). Ethanol groups analyses showed no significant condition $(F(2,40)=0.68, p<0.511)$ effects, but a significant condition $\times$ period interaction was found $(\mathrm{F}(4,162)=3.37, \mathrm{p}<0.011)$. The univariate analysis was significant for movement time only $(p<0.005)$, 

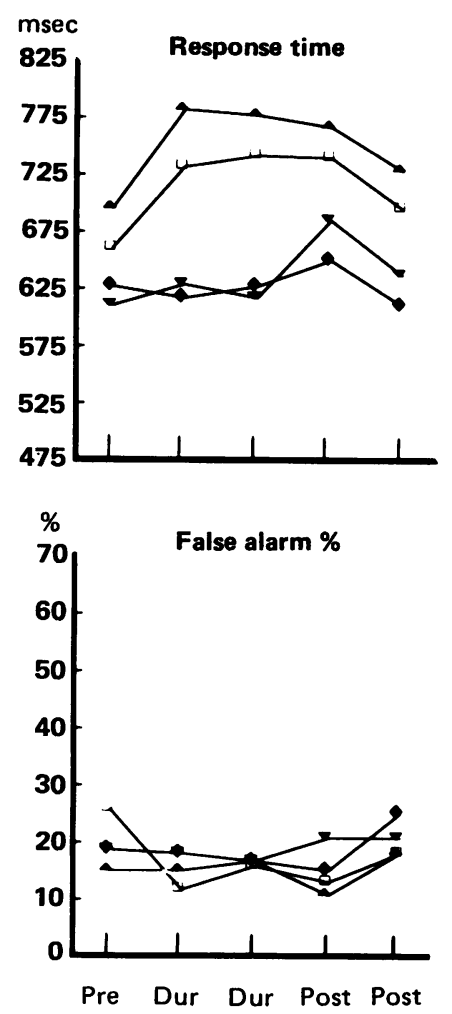

1-2 h 3-4 h 5-6 h 7-8 h 23-24 h

Fig 3 Ethanol response measurements in dual task.

and only in the post: $7-8 \mathrm{~h}$ test period (LSM $\mathrm{p}<$ $0.001)$. The ethanol group showed improvement $(9 \%)$ over the control group.

\section{MEMORY SCANNING (STERNBERG)}

Multivariate analyses of the chemical groups showed a significant condition $\times$ period interaction (F $(24,552)=1.84, \quad p<0.009)$. Results from univariate analysis showed significance only with the negative intercept (condition $\times$ period, $p<0.0012$ ) in the exp: $5-6 \mathrm{~h}$ period (LSM $\mathrm{p}<0.04$ ) for the acetone/MEK group and in the exp: $5-6 \mathrm{~h}$ period (LSM $p<0.03$ ) and post: $7-8 \mathrm{~h}$ period (LSM $\mathrm{p}<0.01)$ for the MEK group. These groups had 8$12 \%$ greater score improvements than controls. A similar trend existed for the acetone group but the differences were not significant.

Significant differences $(p<0.0001)$ between the baseline scores and the post: $23-24 \mathrm{~h}$ scores were evident, however, which clouds the interpretation of these results. Collapsing across all four response measurements, scores improved $18 \%$ over baseline. Positive slope scores showed the greatest
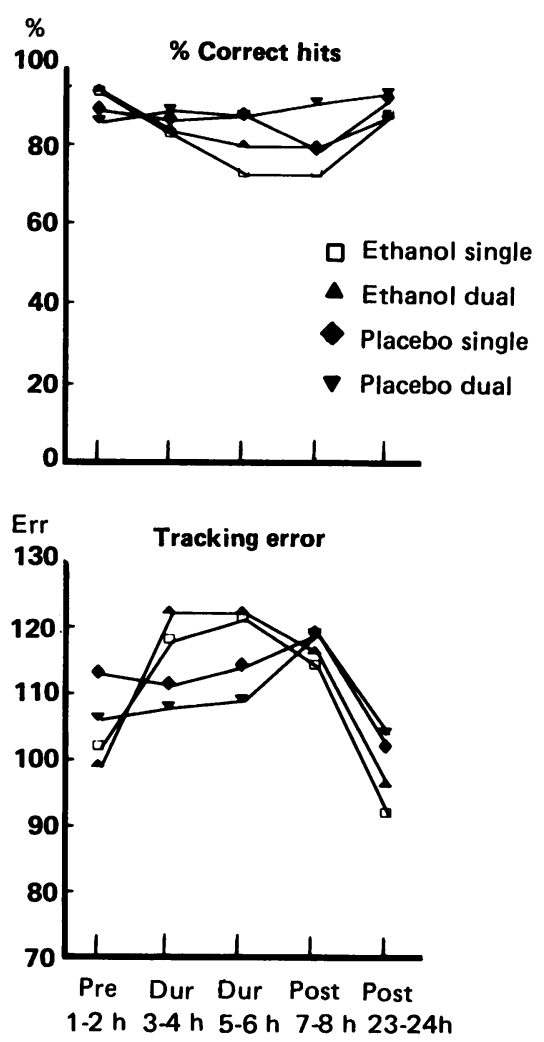

improvement. With these significant learning effects the results from this test are largely uninterpretable more pretest practice was needed. With the greatest improvements occurring on the positive slope scores subjects were apparently still refining their memory search strategies.

POSTURAL SWAY

Preliminary analyses were run to determine which response measurements were correlated, the mose sensitive, and whether sex differences existed. The model used in the final analysis combined sex but use $\$$ periods and eye condition (open versus closed) as separate factors. MANOVA analysis of the chemical. treatment groups showed no significant condition (F $(15,227)=0.73, p<0.75)$, condition $\times$ eye condition $(F(15,224)=1 \cdot 14, p<0.32)$, or cons dition $\times$ period $(F(30,674)=0.87, p<0.66)$ effects Although no significant differences were present, there were distinct directional changes in the eyes closed condition. Examination of plots of treatment group $\bar{\Phi}$ $x$ period means indicated sway measuremen ${ }^{f}$ increases for the acetone group, whereas MEK, the् 


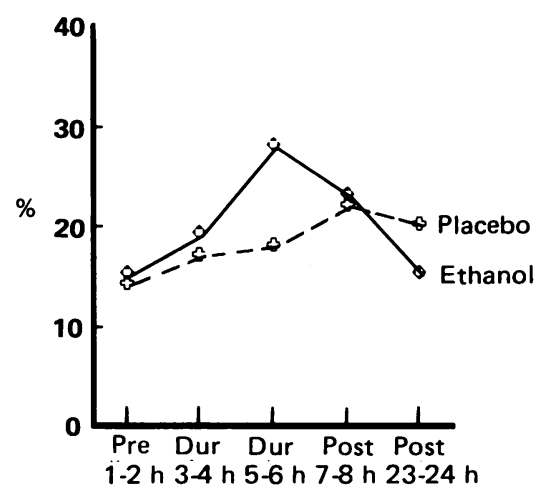

Fig 4 Ethanol response measurements (false alarm \% rate) in visual vigilance task.

acetone/MEK, and control group either plateaued or declined. The changes were most pronounced in the exp: 5-6 $\mathrm{h}$ period (length, area, and velocity), where the acetone group increased $10 \%$ from baseline on length, $10 \%$ on velocity, and $26 \%$ on area, whereas the control changes were $0 \%, 1 \%$, and $3 \%$, respectively. The large standard deviations relative to the means probably resulted in statistically non-significant results.

Ethanol MANOVAs were condition (F $(3,39)$ $=2.06, p<0.09)$, condition $\times$ eye condition $(F$ $(5,37)=1.51, p<0.21)$, and condition $\times$ period $(F$ $(10,164))=0.57, p<0.839)$. A potential ethanol effect seems indicated by the 0.09 MANOVA for condition.

\section{POMS}

No significant condition $(F \quad(18,207)=1 \cdot 31$, $\mathrm{p}<0.19)$ or sex $(\mathrm{F}(6,73)=1.99, \mathrm{p}<0.08)$ effects were noted but there was a significant condition $\times$ sex interaction $(F(18,207)=1 \cdot 76, p<0.03)$. The only significant effect from univariate analyses was on the anger hostility scale $(p<0.02)$. LSM comparisons for condition $\times$ sex showed that the effect was significant for men exposed to acetone $(p<0.001)$ but not for women. Women averaged 42 on the anger hostility scale after exposure and dropped to 41 the following day, a $2 \%$ change. Men changed $29 \%$, dropping from 59 to 47 . No significant MANOVAs were present in the ethanol group's analysis.

\section{Discussion}

This research was intended to measure neurobehavioural changes that occur during the short duration exposure to ketones or ingestion of ethanol. Biochemical indicators for blood and breath levels, as summarised in table 3 and detailed in Brown et al, ${ }^{12}$ document that the desired body burden levels were attained. With some extrapolation, because of sample time differences, acetone blood and breath concentrations are consistent with previous reports. ${ }^{316}$ MEK blood concentrations agreed with our previous work. ${ }^{5}$ The higher 3-4 ppm breath levels in the present study were probably due to reduced delay between exit from the exposure chamber and obtaining samples. Extrapolating from our two hour blood ethanol sample, and assuming the standard $15 \mathrm{mg} \%$ an hour drop, most subject's blood alcohol concentration (BAC) peaked between 0.07 and $0.08 \%$ at the one hour mark.

The neurobehavioural test results indicate some mild but detectable effects in the chemical treatment conditions on the auditory tone discrimination task, and in one chemical condition (acetone) in men only on the POMS test. There was also some indication, although not statistically significant, of some acetone related changes on postural sway. In the auditory tone test (single presentation) acetone exposures at $250 \mathrm{ppm}$ increased the response time to correct hits and the false alarm $\%$ rate. The false alarm $\%$ rate was the most dramatically affected, as it was directional by comparison with the two other chemical groups and the controls. It occurred in both exposure periods and was also present in the post 7-8 h period. The response time measurement was significant in the exp 3-4 h period and the post 7-8 h period but not in the exp 5$6 \mathrm{~h}$ period. The two other chemical exposure groups (acetone/MEK and MEK) also differed significantly from controls on false alarm \%, but these differences appeared to be due to the large performance score improvements that the control group made from baseline (the control group had the highest baseline rate of any group) to the first exposure period (see figure 2). There were no group differences on $\%$ correct hits, so with acetone affecting two of the three measures on this test (auditory tone) and the other two chemical groups only differing on one measure, but displaying similar false alarm rates to the control group (all within $5 \%$ of one another) for the three test periods, the most likely chemical effects occurred with the exposure to acetone.

The auditory tone task in single presentation was probably an understimulating task for most subjects and possibly more sensitive to chemical effects as there were non-significant chemical effects in dual presentation (with tracking). The increase in response time probably indicates some mild depression, but the false alarm \%, a ratio of false alarms to the total number of hits + false alarms, is more difficult to explain. Coupled with the lack of stimulation and difficulty of the tone detection, the absence of substantial improvement in the acetone group may indicate that 
these subjects were more willing to guess under the exposure to this chemical. As noted below, ethanol showed a more consistent depressant effect by reducing correct hits and the false alarm rate. A delay in test score improvement with an exposure to acetone was also evident in the six day exposure experiment of Matsushita et al. ${ }^{3}$

Magnitude of effects and the capability of a test to detect effects were measured by the ethanol conditions. The dual task showed the most dramatic ethanol effects, which may have been due to this test's position in the test order (during the one hour peak blood ethanol concentrations). Ethanol caused statistically significant differences from controls on all the auditory tone discrimination measures in single presentation, and on all measures except false alarm \% in dual presentation. Tracking performance was affected by ethanol only in dual presentation but not as severely as were the auditory tone measures. These findings are consistent with other research on the effects of alcohol on divided attention tasks. ${ }^{17}$ The visual vigilance false alarm \% (MANOVA condition $\times$ period, $p=0.058$ ) and some postural sway measures (MANOVA condition, $p=0.09$ ) combined, are also suggestive of ethanol effects. Test order and the single administration of ethanol with its resultant rapid peak body burden level may have diminished the total effect of the ethanol condition on the tests which failed to show statistically significant performance changes.

The strength of the acetone effects in this study may be interpreted in several ways. Statistically significant results occurred in only one of the neurobehavioural tests and on only one scale of the psychological test. They also occurred on only two of the several neurobehavioural measures analysed. The performance differences on these two measures (dual task response time and false alarm \%) compared with controls was roughly $11-12 \%$, which is mild. The Matsushita et al study which exposed subjects for six consecutive days found simple reaction time differences over the full six days of about $5 \%$ at $250 \mathrm{ppm}$ and $10 \%$ at $500 \mathrm{ppm} .{ }^{3}$ It is also interesting that the significant acetone results, which occurred with some consistency throughout the two exposure periods and even into the post: $7-8 \mathrm{~h}$ period, parallel to some extent the blood concentration for this chemical (see fig 2). Blood concentrations continued to rise throughout the four hour exposure, and the post: 7-8 hour sample was still close to the two hour sample. Neither the MEK group nor the acetone/ MEK group had concentrations this high.

In summary, this study detected some mild but statistically significant effects to a four hour exposure of acetone at $250 \mathrm{ppm}$ on two measures in an auditory tone discrimination task and one scale on the POMS. The performance changes, when detected, showed some persistence, which paralleled the venous blood $\overline{\bar{Q}}$ concentrations of acetone. This gives some indication? that tolerance did not develop at the tested concentra- $\stackrel{\mathbb{Q}}{\circ}$ tions. The acetone effects, however, were not as broad as the ethanol effects, and they occurred in ano understimulating task that may have been subject to 0 other unknown influences, perhaps including a을 spurious result due to the large number of dependent $\frac{\bar{s}}{5}$ measures used in the statistical analyses. The findings $\propto$ should be taken as an indication that more research iso needed.

No statistically significant effects were detected with. the exposures to MEK at $200 \mathrm{ppm}$, and there were no $\overrightarrow{\vec{\omega}}$ statistically significant interaction effects with the $\omega$ combination exposure of acetone (125 ppm) and MEK $(100 \mathrm{ppm})$. The latter finding thus provides 3 some indication that there was no potentiation of $\dot{ }$ के acetone caused by MEK on the central nervous systemiv domains tested in this study at the current $\mathrm{NIOSH}_{-}^{-}$ recommended exposure limits.

The following contributed significantly to the outcomeof the study: William D Brown, Jay Klemme, ${ }_{\mathbb{D}}$ Richard L Hawks, Amit Bhattacharya, Randy Smith, Pam Schumacher, and Margaret Regan.

The mention of product names in this publication inc $\overrightarrow{0}$ no way constitutes endorsement by the Nationale Institute for Occupational Safety and Health.

In the interest of reducing the length of the paperr technical details on the performance tests, test apparatus, experimental procedures, chemical genera-迹 tion/monitoring methods, and additional results analysis/data tables are omitted. This information may be requested from the authors.

\section{References}

1 Curtis M, Keller LW. Exposure issues in the evaluation of solvent effects: report of the workshop session on exposure issues. In: $\bar{\sigma}$ Cranmer JM, Goldberg L, eds. Proceedings of the workshop on neurobehavioral effects of solvents. Neurotoxicology 1987;7: 5-24.

2 Krasavage WJ, O'Donoghue JL, DiVincenzo GD. Ketones. In: Clayton GD, Clayton FE, eds. Patty's industrial hygiene and $\mathrm{O}$ toxicology. Vol IIC. New York: John Wiley, 1982:4709-800.

3 Matsushita T, Goshima E, Miyakaki N, Maeda K, Takeuchi Y, $\frac{D}{O}$ Inoue $\mathrm{T}$. Experimental studies for determining the MAC value of acetone. 2. Biological reactions in the "six-day exposure" to N acetone. Sangyo Iqaku 1979;11:507-15.

4 Nakaaki K. An experimental study on the effect of exposure to $\mathrm{N}$ organic solvent vapor in human subjects. Journal of Science of $\mathrm{N}$ Labour 1974;50:89-96.

5 Dick RB, Setzer JV, Wait R, et al. Effects of acute exposure of $\underset{\gamma}{\sigma}$ toluene and methyl ethyl ketone on psychomotor performance. Int Arch Occup Environ Health 1984;54:91-109.

6 US Department of Health and Human Services, Public Health Service, Centers for Disease Control. NIOSH recommenda- : tions for occupational safety and health standards. $M M W R$ 

suppl 35(1s), 1986.

7 Code of Federal Regulations 29 CFR 1910.1000, table Z-1, Z-2, June 1981. Washington; US Printing Office, 1981.

8 Mackworth NH. Researches on the measurement of human performance. In: Sinaika HW, ed. Selected papers on human factors in the design and use of control systems. New York: Dover, 1961:174-331.

9 Sternberg S. Memory scanning: new findings and current controversies. QJ Exp Psychol 1975;27:1-32.

10 McNair DM, Lorr M, Droppleman LF. EITS manual for the profile of mood states. San Diego: Educational and Industrial Testing Service, 1981.

11 Jones RH, Ellicott MF, Cadigan JB, Gaensler EA. The relationship between alveolar and blood carbon monoxide concentrations during breath-holding: simple estimate of COHb saturation. J Lab Clin Med 1958;51:553-64.
12 Brown WD, Setzer JV, Dick RB, Phipps FC, Lowry LK. Body burden profiles of single and mixed solvent exposures. $J$ Occup Med 1987;29:877-83.

13 SAS Institute Inc. SAS User's guide: statistics. Version 5. Cary, NC:SAS Institute Inc, 1985.

14 Schaffer JW. On the analysis of repeated measures over time in medical pharmacological, and behavioural research. $J$ Behav Med 1979;2:221-38.

15 Barker HR, Barker BM. Multivariate analysis of variance (MANOVA). Alabama: University of Alabama Press, 1984.

16 Tada O, Nakaaki K, Fukabiori S. An experimental study on acetone and methyl ethyl ketone concentrations in urine and expired air after exposure to those vapors. Journal of Science of Labour 1972;48:305-36.

17 Moskowitz H. Psychological tests and drugs. Pharmacopsychiatry 1973;6:114-26.

\section{Correspondence and editorials}

The British Journal of Industrial Medicine welcomes correspondence relating to any of the material appearing in the journal. Results from preliminary or small scale studies may also be published in the correspondence column if this seems appropriate. Letters should be not more than 500 words in length and contain a minimum of references. Tables and figures should be kept to an absolute minimum. Letters are accepted on the understanding that they may be subject to editorial revision and shortening.

The journal now also publishes editorials which are normally specially commissioned. The Editor welcomes suggestions regarding suitable topics; those wishing to submit an editorial, however, should do so only after discussion with the Editor. 